\title{
Le Départ
}

Jan Pallister

Au fond de 1'escalier que je descends

un souvenir cuisant

couvre ma vue:

Or, quel fantôme, revenant

d'un passé si lointain, suggère à mon coeur

le déjà-vu, le déjà vécu, quelque ancien bonheur, ou est-ce malheur?

Je descends la triste rue.

I1 y a pourtant de la congruité ici,

de la cohésion,

car je ne vois plus rien que ta nuque nue,

que tes yeux, que tes sourcils noirs,

ta belle figure

(le sommeil - un grand soleil - glisse goutte à goutte dans tes yeux);

tu es dorénavant ma seule réalité,

mon paradis

désespéré;

je ne pense plus qu'à toi; je lis 
dans ton existence ma vie passée, la distillation pure de mon présent, fusé à l'avenir.

Je descends à l'enfer...

Tout fond dans une mer

d'oub1i:

je ne peux rien retenir;

et je te crie de ma folie,

je m'écrie...

oui, je te crie

de 1'obscurité épaisse

où tu me laisses:

"miracle si je reviens!'

et puis

je n'entends plus rien, non, je ne sens plus rien, sinon ta voix, ta main.

Bowling Green State University 